\title{
ARTICLE: GUEST INTRODUCTION TO SPECIAL ISSUE
}

\section{Great Problems of Grand Challenges: \\ Problematizing Engineering's Understandings of Its Role in Society}

\author{
Erin Cech
}

Department of Sociology, Rice University, ecech@rice.edu

The U.S. National Academy of Engineering's Grand Challenges for Engineering report has received a great deal of attention from legislators, policymakers, and educators, but what does it entail for social justice considerations in engineering? This article situates the Grand Challenges report as a cultural artifact of the engineering profession-an artifact that works to reinforce engineering's professional culture, recruit new members, and reassert engineering's legitimacy in the $21^{\text {st }}$ century. As such, the Grand Challenges report provides a unique opportunity to understand and critique the role engineering envisions for itself in society. The articles in this special issue of IJESJP identify four central critiques of Grand Challenges: authorial particularism, double standards in engineering's contributions to these challenges, bracketing of the "social" from "technical" realms, and deterministic definitions of progress. These critiques call for increased reflexivity and broadened participation in how engineers define problems and attempt to solve them.

KEYWORDS: Grand Challenges, National Academy of Engineering, participation, reflexivity, technicalsocial division

\section{INTRODUCTION}

\begin{abstract}
Throughout human history, engineering has driven the advance of civilization. From the metallurgists who ended the Stone Age to the shipbuilders who united the world's peoples through travel and trade, the past witnessed many marvels of engineering prowess.... In the century just ended, engineering recorded its grandest accomplishments. The widespread development and distribution of electricity and clean water, automobiles and airplanes, radio and television, spacecraft and lasers, antibiotics and medical imaging, and computers and the internet [sic] are just some of the highlights of a century in which engineering revolutionized and improved virtually every aspect of human life. (National Academy of Engineering, 2008, p. 1-2)
\end{abstract}

With a statement like this, it is hard to imagine how any other profession or realm of expertise might have contributed to societal change in the last two millennia. It is also hard to recognize that the engineering profession, as a legitimated entity separate from the work of artisans, craftspeople, and scientists, has only existed since the mid-19th century (Hughes, 2005). These epically-worded sentiments are just a few of many included in the introduction to the Grand Challenges of Engineering, a 50-page report produced by the National Academy of Engineering to document important challenges facing "civilization's continuing advancement" and the role of engineering in solving those challenges. More than simply a "to-do" list of priorities envisioned by leading engineers, this report is an important moment when the profession makes clear and bold statements about its role in society. But, in this moment, which has commanded the attention of 
legislators, policy makers, educators, and current and future engineers, the Grand Challenges makes scarce reference to the ethical justification for the pursuits it proposes. It also sidesteps the ramifications of these pursuits for social justice. By defining engineering responsibilities (and, indeed, human progress itself) as narrowly technological, the Grand Challenges closes off space for considering the professions' responsibilities (or past and present contributions) to social (in)justice in the United States and abroad.

The authors of the articles in this special issue use the Grand Challenges as an opportunity to critically examine engineering's self-presentation and to ask important questions about how the profession's role in society might be envisioned differently. To set the stage, the present article frames the Grand Challenges as an historical and cultural artifact and explains why it is deserving of investigation. I discuss what the report means in the broader context of a profession acting to secure its legitimacy and power in society. I then describe the four central critiques that emerge from the articles in this issue and end by discussing what each of these critiques call for: greater reflexivity and broader participation in the search for engineering problem definitions and solutions.

The Grand Challenges report is a product of the United States' National Academy of Engineering (NAE), arguably the most prestigious organization within the engineering profession in the U.S. Engineers elected to be fellows of NAE are understood to be leaders in their subfields in industry and academia and are often called upon to advise technology and education-related policymaking. A panel of eighteen professionals, all in science and engineering fields, and most with primary ties to the United States (Riley, this issue), was charged by the U.S. National Science Foundation with crafting the report. The Grand Challenges authors selected fourteen challenges they understood to be achievable (as well as sustainable) that would "help the people and the planet thrive" (p. i). (See Table 1 for a list of the fourteen challenges.) The Grand Challenges website offers a place for the general public to submit comments on the challenges (www.engineeringchallenges.org), although it is unclear how, if at all, these comments affect the subsequent web content surrounding the report.

In addition to the report itself, the Grand Challenges website offers a 6-minute highquality video narrated by panel members, a "K12 Partners Program" with lesson plans and pedagogical suggestions, a "Grand Challenges Scholars Program," and an annual poster contest. As several of the articles in this issue discuss, the report has circulated widely among engineering educators, lawmakers, and industry leaders.

The influence of this report alone, as an enticement for future engineers and reminder of engineering's greatness for the converted, makes it an important site for investigation. However, Grand Challenges is more than an advertisement of engineering's power and prominence. This report is a cultural artifact representing the profession's statement of its role in society. As such, it serves several purposes for the engineering profession. First and foremost, Grand Challenges is a claim for the

\begin{tabular}{l} 
Table 1: \\
Fourteen "Grand Challenges" of Engineering \\
\hline Make solar energy economical \\
Provide energy from fusion \\
Develop carbon sequestration methods \\
Manage the nitrogen cycle \\
Provide access to clean water \\
Restore and improve urban infrastructure \\
Advance health informatics \\
Engineer better medicines \\
Reverse-engineer the brain \\
Prevent nuclear terror \\
Secure cyberspace \\
Enhance virtual reality \\
Advance personalized learning \\
Engineer the tools of scientific discovery \\
\hline
\end{tabular}

Table 1:

Fourteen “Grand Challenges" of Engineering

Make solar energy economical

Provide energy from fusion

evelop carbon sequestration methods

Provide access to clean water

Restore and improve urban infrastructure

Advance health informatics

Engineer better medicines

Reverse-engineer the brain

Secure cyberspace

hance virtual reality

Advance personalized learning

gineer the tools of scientific discovery 
legitimacy of the profession in $21^{\text {st }}$ century societies. Such legitimacy is by no means guaranteed or perpetually conferred to established professions (Abbott, 1988). One could imagine several challenges to engineering's legitimacy: some people might say that engineering was once an important profession, but its current relevance to society is diminishing. Others might say that trends toward sustainability, simplicity, and reusability render engineering's grand visions of "hightech" solutions no longer desirable. In the face of such real or imagined critiques, Grand Challenges presents a forceful argument (perhaps one resembling a politic of fear) that the engineering profession deserves to remain at the table among the most respected professions in the world.

Such claims to legitimacy are neither new nor unique to engineering (Hughes, 1975, 2005; Nye, 1992. Amy Slaton's article in this issue chronicles the history of similar claims of engineering's legitimacy, dating back to its beginnings as a profession. Indeed, the establishment of legitimacy is the central feature of professionalization, the process by which a collection of jobs, skills and knowledge carve out a social and cultural space separate from other professions, secures a monopoly over those jobs, skills, and knowledge, and gains recognition for itself as a profession (Freidson, 1973; Gorman \& Sandefur, 2011). However, a profession's fight for legitimacy is not over once it has established legal recognition and credentialing procedures; professions must continually reassert their relevance in a changing society and protect their jurisdiction of practice and expertise from encroachment by other professions (Abbott, 1988). The Grand Challenges report represents a relatively rare example of a profession explicitly communicating its relevance and patrolling its own jurisdictional boundaries.

Second, Grand Challenges is simultaneously a celebration and a reinforcement of engineering's professional culture. As the socio-cultural glue that unites the various tasks and jobs into a single "social collective" (Grusky, 2005; Weeden \& Grusky, 2005), the professional culture of engineering encompasses the rich myths, rituals, and meaning systems that give engineering its particular flavor and delineate its values and priorities from other professions. This culture is reinforced through professional journals, conferences, and interactions between profession members, and is reproduced in new generations through professional socialization in engineering education (Becker et al., 1961; Schleef, 2006; Trice, 1993). But professions also require platforms to re-tell their tall tales and origin myths to a wider audience. The Grand Challenges report, particularly the sections of the introduction quoted above, aptly serves this purpose. It celebrates engineering's (imagined) origins in some of the most consequential technical innovations of human history (fire, the wheel), claiming a direct lineage from those grand inventions to engineers of today and the work they envision for the future. This cultural history is certainly meant to inspire awe from those outside the profession, but the more probable effect is that it invokes pride among engineers, reminding profession members of their collective greatness.

More importantly, the Grand Challenges endeavor reinforces the values and norms most important to engineering culture. The report clearly emphasizes efficiency, economy, and large-scale and complex solutions over simpler "low-tech" solutions, and purely "technical" problem-solving over access and engagement with "social" or "political" elements (a critique discussed in more detail below). The beliefs and norms hidden between the lines of specific challenges and their solutions serve as reminders to engineers of what is valued most in past, present and future engineering work. The engineer-as-hero novels of the 1880s, which presented (men) engineers as cowboy-like figures who saved the nation through grandiose feats of engineering and always "got the girl" in the end (Nye, 1992) served a similar culture-reinforcing purpose over a century ago.

Finally, and more overtly, Grand Challenges is a recruitment tool for young people. As noted above, NAE developed spin-off materials to be used in K-12 education to entice students to join the ranks 
of engineering so they, too, could "revolutionize" and "improve" virtually "every aspect of human life" (p. 2). (The Marines' well-phrased slogans, TV commercials, and video games are perhaps the most visible examples of recruitment tools used by professions in the U.S.). This recruitment tool may have been the impetus behind the U.S. National Science Foundation's request that NAE create the Grand Challenges report in the first place.

All professions engage in similar processes to secure their continued legitimacy, celebrate their accomplishments, reinforce their professional culture, and recruit new members. But, compared to other professions, engineering's vision of its own social utility has historically been particularly vast and encompassing (Hughes, 2005; Nye, 2006; Slaton, this issue).

Thus, the Grand Challenges report is an important cultural and historical site for understanding the current state of the profession-the role it envisions for itself in the past and in the future, its tools for recruiting the next generation of profession members, the values and norms most central to its professional culture and, thus, its very approach to the work of problem definition and problem solving. This lengthy treatise on the state of the profession through the profession's own words provides scholars with an opportunity to understand and critique the profession and to suggest alternate courses of action.

Although the report is a useful vehicle for understanding the engineering profession, leveling critiques at the Grand Challenges for Engineering comes with own challenges. The claims of legitimacy embedded in this document means that questioning the Grand Challenges report may be misunderstood as critiques of the very legitimacy of the engineering profession itself. After all, the report represents that which is held most dear in the culture of engineering. However, critiques of the Grand Challenges-especially those that can be extended to the profession itself-are not an affront to the arguably beneficial work of much of the engineering profession in the past and present, nor do they deny that many of the fourteen challenges are indeed important problems facing $21^{\text {st }}$ century societies (at least post-industrial ones). As Catalano (this issue) points out, the authors critique the role that engineering sets out for itself in the present and future, not whether engineering should have a role at all. As I describe in the next section, these critiques neither deny the legitimacy of engineering as a profession, nor reject engineering expertise, but rather critique the particular context out of which these challenges, and their proposed solutions, are defined. I next describe the four central themes around which the authors in this issue offer their analysis of the Grand Challenges for Engineering and discusses how these critiques lead to a deeper understanding of engineering's role in social justice.

\section{THEMES OF CRITIQUE}

While the authors in this issue approach the Grand Challenges from different theoretical perspectives and employ different methodologies, several themes of critique emerge out of these articles. Delineating these themes allows the articles to point collectively to the most troubling aspects of engineering as they are manifested in the Grand Challenges report. I describe the four themes below and then discuss the recommendation for change that underlies all these critiques: the need for reflexivity and increased participation in engineering problem definition and solution.

\section{Authorial Particularism}

The first theme emerging out of several of the articles concerns the authorship of the Grand Challenges. Who participated in selecting these challenges and recommending particular solutions to them? Do the particular positions and interests of the committee members skew the representativeness of the challenges and solutions themselves? Riley's examination of the Grand 
Challenges committee finds that all authors are either engineers or scientists, most of them work in corporate organizations or research institutions, and only three of the eighteen committee members are women (and only one of those women is an engineer). Nieusma and Tang echo Riley's observation that many of the fourteen challenges and their proposed solutions are curiously particular to committee members' own companies or research expertise. For example, fixing the nitrogen cycle and carbon sequestration-two very specific issues in the much broader problem of global climate change-are both domains of interest to one individual committee member (Riley, this issue). This particularism begs the question: would a more interdisciplinary and genderbalanced committee have arrived at a different set of challenges and proposed engineering solutions?

Perhaps more disconcerting, there is no evidence that the committee recognized this particularism; there is no acknowledgement that the makeup of the committee itself may have biased the types of challenges it found most pressing. This is reminiscent of the "god trick" identified by Donna Haraway (1988), whereby scientists and technologists presume (and are presumed to have) a "view from nowhere" from which they can define priorities and describe "reality." Acknowledgement of the committee members' own situatedness may have led to different conclusions about engineering challenges and solutions.

Authorial particularlism is most evident in the skewing of many of the problems and solutions to well-off members of post-industrial nations. Put bluntly, many of them are wealthy Americans' problems. Some of the challenges (e.g. perfecting virtual reality and reverse-engineering the brain) are simply irrelevant to poor populations struggling to access basic human and social necessities (e.g. food, shelter, voting rights, education and job training). As Riley and Slaton both discuss, some of the challenges are relevant to most populations (better education and healthcare) but the particularistic solutions offered are aimed at those who already have access to the best education and healthcare available. Individualized computer learning, for example, seems irrelevant in classrooms struggling to afford textbooks and pencils, let alone laptops, for students (Kozol, 1991; Riley, this issue), and the perfection of personalized healthcare à la implantable microchips seems out of touch in relation to the millions of people around the world without access to basic antibiotics (Slaton, this issue).

The committee's choice to prioritize these aspects of education and healthcare-presumably because they bring opportunities for complex and innovative engineering design-is not without consequence for social justice. The uptake of the Grand Challenges report by policymakers may mean that millions of research and investment dollars follow these particularistic solutions. Not only do the solutions suggested in the Grand Challenges ignore the plight of the underprivileged, but very real monetary and political capital investments inspired by this report could make health and education gaps between the wealthy and the poor (e.g. Deaton, 2003; DeNavas-Walt, Proctor, \& Smith, 2007) substantially greater, not smaller.

\section{Double Standards: Acknowledging Engineering's Contributions to Solutions, Not Challenges}

Second, several authors in this issue see a blatant double-standard in the Grand Challenges' conceptualization of engineering's role in the fourteen challenges. The report denotes the heroic role engineers play in addressing the problems facing modern societies, providing key technological solutions that can propel "civilization" beyond these challenges. However, there is no acknowledgement of the contributions of engineering design to the existence of these challenges in the first place. Several authors give examples of these double standards: Riley points out that the Grand Challenges authors write about the grave dangers of nuclear terror, but steer clear of 
acknowledging engineers' role in the Manhattan project which developed that very technology (also see Florman, 1994). The threat of biological weaponry, designed by engineers in state-funded laboratories, is discussed in a similarly one-sided manner. Blame for these problems are placed squarely in the laps of others (e.g. "terrorists," "cyber criminals") or are considered the effect of unchangeable social mores (e.g. "It remains unlikely that fossil fuels will be eliminated from the planet's energy-source budget any time soon" [Grand Challenges p. 3]). There is little acknowledgement of engineers' contributions to these challenges-either through their design work, or their complicit participation in the socio-technical systems that perpetuate these challenges.

This double standard ignores the half-century of critique of technological change in general and the critique of the development of nuclear and biological weaponry in particular. As Slaton notes, there is a long history of critique of engineering work, from post-World War II fears over nuclear technology to current concerns about the environment. Grand Challenges is written as though it were in the midst of the era of the technological sublime at the turn of the $20^{\text {th }}$ century (Nye, 1992, 2006). But, even Samuel Florman states in his decidedly sympathetic ode to the profession, The Existential Pleasures of Engineering,

The plaintive call for a new engineering expresses a yearning to return to a time when engineers fancied themselves... 'redeemers of mankind' and 'priests of the new epoch.' With the religion of Progress lying in ruins about us, we engineers will have to relinquish, once and for all, the dream of priesthood, and seek to define our lives in other terms. (1994, p. 41)

Social change in the 1960s and 1970s that ushered in a more critical understanding of technology (Herkert, this issue) makes it no longer possible for engineering to remain blissfully unselfconscious about their profession's contributions to the central challenges societies face, including those documented in this report. Yet, because of the emphasis on objectification and lack of contemplative epistemologies (Catalano, this issue), engineering's cultural perspective on its own work would struggle to recognize past and present engineering works as anything but heroic acts of technological prowess.

More consequentially, as Nieusma and Tang argue, this double standard immunizes engineering from the need to take a critical look at its practices of problem definition and solution. Ignoring the profession's contributions to these challenges allows engineering to remain relevant to society and to protect its claim to being the "saviors" of "civilization" from climate change, cyberterrorism, etc, while at the same time extracting itself from blame-as well as from any responsibility to engage in legislative and policy decisions about the consequences of engineering work for social justice (Nieusma \& Tang, this issue).

\section{Bracketing the "Social" and "Political" from the "Technical"}

Related to-and partly undergirding-the double standard in the Grand Challenges report is the explicit extraction of "technical" matters from the social, political, ethical and cultural realms of these challenges. Grand Challenges simultaneously positions the engineering profession with sole responsibility for strictly technical factors embedded within those challenges while bracketing (or simply ignoring) the non-technical matters, such as social justice, that are inextricably linked to such "technical" dimensions. This separation of the "technical" from the "social" is part of an enduring propensity in the engineering profession for dualistic styles of thought (Buciarelli, 1994; Vincenti, 1990). One particular dualism-the "technical/social dualism"-was first identified by Sally Hacker (1981) and expanded by Wendy Faulkner's work (2000, 2007). According to this cultural belief, purely "technical" tasks and knowledge can be extracted from the "messiness" of the 
social world, and such technical realms are most prestigious and meaningful to engineers. Social or political considerations beyond cost efficiency are not only devalued, they also threaten the "purity" of engineering work (Cech, in press).

As many of the authors in this issue argue, this dualism plays a starring role in the Grand Challenges report. Not only are the solutions to the stated problems exclusively technological (e.g. desalination as a solution to water shortages), they rarely mention the need for engineers to engage with policy makers and other professionals to deal with the dimensions of these challenges that are considered outside the "technical" realm. This particular framing translates vastly complex social problems into strictly technical problems (Catalano, this issue; Nieusma \& Tang, this issue). Such framing suggests a rather profound lack of understanding of the complexity of these challenges, particularly the ways that technological solutions are always inherently interwoven with larger socio-political contexts (Hughes, 1987; Mackenzie, 1990; Pinch \& Bijker, 1987). As such, both the definition of these problems and the proposed solutions to them are naive at best and dangerously reductive at worst (Riley, this issue; Slaton, this issue).

As a result of this bracketing, there is little emphasis in the Grand Challenges report on engaging the expertise and skills of other professionals (political scientists, sociologists, historians, science and technology studies scholars, ethicists, etc.) to solve problems cooperatively. These professions are certainly not making any claims to the jurisdiction of engineering work, so they are not an immediate threat to the relevance of engineering to society. However, the rhetoric of the Grand Challenges resists recognizing that other realms of expertise are necessary and important for addressing these challenges. Consequently, expert (and non-expert) voices promoting social justice are excluded from engineering conversations.

More troubling, Nieusma and Tang and others point out that not only are the contributions of various "social" or "political" constituencies ignored, they are understood as roadblocks to engineers' work (Riley, this issue; Nieusma \& Tang, this issue). The introduction to Grand Challenges states that "government and institutional, political and economic, and personal and social barriers will repeatedly arise to impede the pursuit of solutions to problems" (pg. 6). Nieusma and Tang quote sections of the Grand Challenges report talking about how teachers "must revamp" their pedagogies so their students benefit from computerized learning, and medical professionals will "have to alter" their procedures to make the best use of health informatics. The Grand Challenges report is, therefore, a call for professional action that puts engineering in a position of dominance over opponents, those with competing viewpoints, and neutral bystanders alike. By bracketing and, in several cases, demonizing the social, political, ethical and cultural dimensions of these challenges, the Grand Challenges report misrepresents the complexities inherent in the challenges themselves, but also shuts down democratic, social justice-oriented avenues for technological decision-making.

\section{Technological Determinism}

The final theme and perhaps most potent critique leveled at the Grand Challenges by the authors in this issue is a critique of the particular (and particularly narrow) definition of progress used in the report. As might be expected from the valuation of the "technical" above all else within engineering culture, Grand Challenges understands progress as a purely technological matter. The report's introduction defines the progression of "civilization" as a steady march toward technological change that results in the antiquation of existing solutions by ever more complex and interconnected technological objects and systems. This technological progression is assumed to be desirable, necessary, and inevitable. 
Herkert (this issue) discusses literature that labels this perspective "technological determinism" (see e.g. Smith \& Marx, 1994). Technological determinism has historically been the predominant way the engineering profession has understood progress (Hughes, 2005; Slaton, this issue), likely because such determinism elevates the engineering profession to prime societal importance. Of course, technological determinism has been criticized as a way of understanding societal change since the 1970s. Historians and science and technology scholars have long argued that understanding societal change as the result of a string of successful inventions belies the social embeddedness of the invention process, and ignores the fact that technologies have no inherent agency or meaning (Hughes, 1987; Marx, 2000; Pinch \& Bijker, 1987). Not to mention, technological deterministic definitions of progress ignore religious, political, environmental, and cultural factors that are interwoven in societal change.

Technological determinism is problematic not only because it is a highly inaccurate depiction of societal change, but also because it closes down any room for questions about whether these endeavors should be undertaken in the first place. Riley notes the lack of ethical considerations in both the ends (should these be the challenges we address?) and the means (should these be the particular-and particularly technical-solutions we attempt?) in solving the grand challenges. If technology is understood as the basis of human progress, then such questions are, by their very nature, illogical. Herkert gives an example of how urban development in the mid $20^{\text {th }}$ century, understood then and now as a sign of "progress," was tremendously destructive to local communities and created more, not less, inefficiencies.

Finally, the Grand Challenges' presentation of social change through technological determinism means that any negative consequences of that change are considered the unfortunate but necessary fallout of a process whose long-term benefit outweighs any short-term harm. As such, social justice considerations over who must shoulder the burden of this "progress" are seen as largely irrelevant. But asking in whose backyards the radioactive dust from fusion will be buried, or who is to be displaced when urban infrastructure is revamped should be central to decision-making about solving these challenges, not tangential to them (Herkert, this issue; Riley, this issue). The Grand Challenges' technological determinism leaves no room for social justice discussions, let alone considerations of how important societal challenges might be solved with low-tech, simple solutions, or without technological change at all.

\section{IMPORTANCE OF REFLEXIVITY AND BROADENED PARTICIPATION FOR SOCIAL JUSTICE}

Together, the critiques offered by the authors in this issue call for two interrelated changes: increased reflexivity, especially about the relation of engineering to social justice concerns, and broadened participation in engineering problem-solving. First, they point to the need for reflexivity - a critical examination of engineers' role in the past, present and future of societies-in both problem definition and problem solution. For the former, Catalano, Herkert, Riley and Slaton argue for the need for engineers to recognize the full spectrum of factors (technical and nontechnical) related to each problem. Asking, perhaps, what non-technical components of these problems inform the role that engineers should (or should not) take in helping to address them (Catalano)? Whose interests does solving the problem serve (Riley)? And, is it really ethically more imperative to seek solutions to these problems rather than other problems (Herkert)? Finally, how can the most egregious areas of a particular problem be identified in a way that considers the welfare of all people, not just those funding or seeking profit from the solution to those problems? 
Second, the scholars here call for reflexivity and broadened participation in the pursuit of solutions to these problems. Who shoulders the burden and who benefits most from any given solution (Herkert, Riley, Slaton)? How can social justice and peace displace profit-making as central metrics in problem-solving decisions? Additionally, how can the expertise and experience of non-engineers be incorporated into the problem-solving process? The voices of other professionals and the broader constituencies impacted by those solutions should be included at various stages in the process.

In both problem definition and solution, reflexivity and inclusion of non-engineering voices requires that engineers recognize and embrace the uncertainty and complexity inherent in the challenges they seek to address (Nieusma \& Tang, this issue). Only by recognizing and being comfortable with the limits of their expertise can engineers actually "help the people and the planet thrive" (p. 1), not just some people, on some parts of the planet.

\section{CONCLUSION}

The Grand Challenges report represents a relatively rare and important moment when the engineering profession (or at least the thought leaders entrusted to speak on the profession's behalf) offers its views about its role in society. As an artifact of the professional culture of engineering, this report provides the opportunity to examine these views and the cultural values, norms, and visions of engineering embedded therein. The critiques offered in this issue-the central themes of which I describe here-are more than just critiques of a single 50-page document. They are critiques of the engineering profession itself. The popularity and prominence to which Grand Challenges has risen makes these critiques all the more timely, relevant and important for work at the intersection of engineering and social justice.

\section{REFERENCES}

Abbott, A. (1988). The systems of professions: An essay on the division of expert labor. Chicago, IL: University of Chicago Press.

Becker, H., Strauss, A., Hughes, E., \& Greer. B. (1961). Boys in white: Student culture in medical school. Chicago, IL: University of Chicago Press.

Bucciarelli, L. L. (1994). Designing engineers. Cambridge, MA: The MIT Press.

Catalano, G. D. (2012). Unlocking the heart of engineering grand challenges: Listening to the quiet voices. International Journal of Engineering, Social Justice, and Peace, 1(2), 152-159.

Cech, E. A. (in press). The (mis)framing of social justice: Why ideologies of depoliticization and meritocracy hinder engineers' ability to think about social injustices. In J. C. Lucena (Ed.), Just engineering: How can engineering education actively promote socially just engineers?

Deaton, A. (2003). Health, inequality, and economic development. Journal of Economic Literature, 41(1), 113158.

DeNavas-Walt, C., Proctor, B. D., \& Smith, J. (2007). Income, poverty, and health insurance coverage in the united states: 2006 (Current Population Reports No. P60-233). Retrieved from U.S. Census Bureau website: http://www.census.gov/prod/2007pubs/p60-233.pdf

Faulkner, W. (2000). Dualism, hierarchies and gender in engineering. Social Studies of Science, 30, 759-792.

Faulkner, W. (2007). 'Nuts and bolts and people': Gender-troubled engineering identities. Social Studies of Science, 37, 331-356.

Florman, S. C. (1994). The existential pleasures of engineering. New York: St. Martin's Griffin.

Freidson, E. (1973). The Professions and their prospects. Beverly Hills, CA: Sage.

Gorman, E. H., \& Sandefur, R. L. (2011). 'Golden age,' quiescence, and revival: How the sociology of professions became the study of knowledge-based work. Work and Occupations, 38(3), 275-302. 
Grusky, D. B. (2005). Foundations of a neo-Durkheimian class analysis. In E. O. Write (Ed.), Approaches to Class Analysis, (pp. 51-81). New York, NY: Cambridge University Press.

Hacker, S. L. (1981). The culture of engineering: Woman, workplace and machine. Women's Studies International Quarterly, 4, 341-353.

Haraway, D. (1988). Situated knowledges: The science question in feminism and the privilege of partial perspective. Feminist Studies, 14, 575-599.

Herkert, J. (2012). Yogi meets Moses: Ethics, progress, and the grand challenges for engineering. International Journal of Engineering, Social Justice, and Peace, 1(2), 109-122.

Hughes, T. P. (1975). Changing attitudes toward American technology. New York, NY: Harper and Row.

Hughes, T. P. (1987). The evolution of large technological systems. In W. E. Bijker, T. P. Hughes, \& T. J. Pinch, (Eds.), The social construction of technological systems: New directions in the sociology and history of technology, (pp. 51-82). Cambridge, MA: MIT Press.

Hughes, T. P. (2005). American Genesis: A Century of Invention and Technological Enthusiasm, 1870-1970. Chicago: The University of Chicago Press.

Kozol, J. (1991). Savage inequalities: Children in America's schools. New York, NY: Crown.

MacKenzie, D. A. (1990). Inventing accuracy: An historical sociology of nuclear missile guidance. Cambridge, MA: MIT Press.

Marx, L. (2000). The machine in the garden: Technology and the pastoral ideal in America. Oxford, UK: Oxford University Press.

National Academy of Engineering. (2008). Grand challenges for engineering. Washington, DC: National Academies Press. Retrieved from http://www.engineeringchallenges.org/?ID=11574

Nieusma, D., \& Teng, X. (2012). The unbalanced equation: Technical opportunities and social barriers in the NAE grand challenges and beyond. International Journal of Engineering, Social Justice, and Peace, 1(2), 137-151.

Nye, D. E. (1992). Electrifying America: Social meanings of a new technology. Cambridge, MA: MIT Press.

Nye, D. E. (2006). Technology matters: Questions to live with. Cambridge, MA: MIT Press.

Pinch, T. J., \& Bijker, W. E. (1987). The social construction of facts and artifacts: Or how sociology of science and the sociology of technology might benefit each other. In W. E. Bijker, T. P. Hughes, \& T. J. Pinch, (Eds.), The social construction of technological systems: New directions in the sociology and history of technology, (pp. 17-50). Cambridge, MA: MIT Press.

Riley, D. (2012). We've been framed! Ends, means, and the ethics of the grand(iose) challenges. International Journal of Engineering, Social Justice, and Peace, 1(2), 123-136.

Schleef, D. J. (2006). Managing elites: Professional socialization in law and business schools. Oxford, UK: Rowan \& Littlefield Publishers, Inc.

Slaton, A. E. (2012). Note to self: Save humanity (a social and cultural history of the "grand challenges"). International Journal of Engineering, Social Justice, and Peace, 1(2), 95-108.

Trice, H. M. (1993). Occupational subcultures in the workplace. Ithica, NY: ILR Press.

Vincenti, W. (1990). What engineers know and how they know it. Baltimore, MD: Johns Hopkins University Press.

Weeden, K. A., \& Grusky, D. B. (2005). The case for a new class map. American Journal of Sociology, 111, 141212. 